\title{
Endoscopy outreach: How worthwhile is it?
}

\author{
M Voss, L M Forward, C A G Smits, R Duvenage
}

To the Editor: Specialist outreach is a strongly promoted strategy for improving the access of rural populations to specialist care. However, the provision of outreach diverts specialist services from their base hospitals, and places services at those base hospitals in jeopardy. In the under-resourced South African context, it is necessary to monitor and evaluate outreach services to see whether they add value to the health service.

An endoscopy outreach programme was initiated in the Winelands/Overberg region of the Western Cape in January 2008. Medical practitioners at the district hospital and its outlying clinics were given open access to endoscopic investigations, guided by the recommendations of the American Society for Gastrointestinal Endoscopy regarding their appropriate use. ${ }^{2}$

To determine both the disease profile of patients referred by GP open access booking and whether providing outreach endoscopy improves access, we prospectively recorded the following indicators:

- Disease profile: the numbers of ulcers and cancers diagnosed at outreach

- Access: the proportion of patients defaulting from ulcer follow-up and the proportion of 'no shows' for appointments.

The data were compared with prospectively determined data from the regional hospital. Differences were subjected to a chi-squared analysis with one degree of freedom. Data for the disease profile and access indicators are shown in Table I. Of the 15 ulcers diagnosed, one was a T1bN0 cancer which was successfully resected.

Our findings were contrary to expectation, with almost twice as many patients seen at outreach having an ulcer. The important implication of this finding is that primary care

Department of Surgery, Worcester Hospital, Worcester, W Cape, and Division of Surgery, Stellenbosch University, Tygerberg

M Voss, MB ChB, FCS (SA)

R Duvenage, MB ChB, MMed (Surg)

Department of Surgery, Worcester Hospital

C A G Smits, MB ChB

Robertson District Hospital, Robertson, W Cape L M Forward, SRN

Corresponding author: M Voss (mvoss@worcestersurgery.co.za)

\begin{tabular}{|c|c|c|c|}
\hline & $\begin{array}{l}\text { Outreach } \\
\text { service }\end{array}$ & $\begin{array}{l}\text { Regional } \\
\text { hospital service }\end{array}$ & $\begin{array}{l}\text { Statistical } \\
\text { significance }\left(\chi^{2}\right)\end{array}$ \\
\hline Ulcers & $15 / 86^{*}(17.4 \%)$ & $118 / 1259^{+}(9.4 \%)$ & $p<0.01$ \\
\hline $\begin{array}{l}\text { Gastric ulcer } \\
\text { defaulters }\end{array}$ & $5 / 10(50 \%)$ & $27 / 88(30 \%)$ & NS \\
\hline 'No shows' ${ }^{\ddagger}$ & $28 / 114(24.7 \%)$ & $238 / 1157(20.6 \%)$ & NS \\
\hline \multicolumn{4}{|c|}{${ }^{*} 10(67 \%)$ of 15 patients had gastric ulcer. } \\
\hline \multicolumn{4}{|c|}{${ }^{\dagger} 88(75 \%)$ of 118 patients had gastric ulcer. } \\
\hline \multicolumn{4}{|c|}{$\ddagger_{\text {Proportion of 'no shows' determined retrospectively. }}$} \\
\hline
\end{tabular}

practitioners select the right patients for endoscopy, and that giving GPs open access to endoscopy services did not result in services being swamped by patients with minor reflux symptoms.

Half of the patients with a gastric ulcer defaulted from follow-up. Although this did not reach statistical significance, the trend appeared worse than default figures from the regional hospital, and required further investigation. Patients referred from outlying clinics often found it difficult to get to the outreach service because planned patient transport services are not designed to serve outreach clinics. Some patients had had to walk over $30 \mathrm{~km}$ to the district hospital on an empty stomach, whereas they would have used an ambulance service to attend an appointment at the regional hospital. Paradoxically, by taking the service closer, we had made access more difficult for them.

We concluded that an open access referral system for GPs resulted in a high yield of ulcer pathology. Indicators of access showed no improvement when compared with patients referred to the regional hospital, which is probably a consequence of rural transport problems. Conventional outreach programmes should be promoted with caution and monitored, as they may deplete services at the base hospital without offering any real benefit to patients; alternative methods of providing specialist support to district hospitals deserve exploration, and local transport must be factored into the planning.

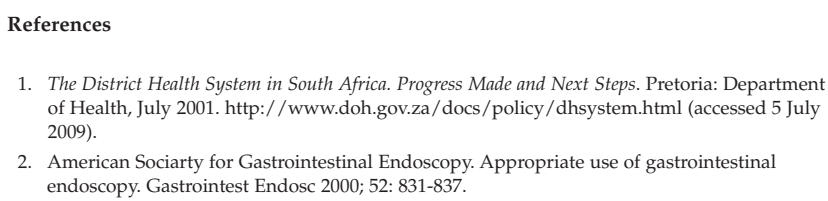

2. American Sociarty for Gastrointestinal Endoscopy. Appropriate use of gastrointestinal endoscopy. Gastrointest Endosc 2000; 52: 831-837.

Accepted 11 September 2009 